\title{
Erratum: Exploiting pattern transformation to tune phononic band gaps in a two- dimensional granular crystal [J. Acoust. Soc. Am. 131, EL475-EL480 (2012)]
}

Fatih Goncu, Stefan Luding, and Katia Bertoldi

Citation: The Journal of the Acoustical Society of America 143, 2182 (2018); doi: 10.1121/1.5031784

View online: https://doi.org/10.1121/1.5031784

View Table of Contents: https://asa.scitation.org/toc/jas/143/4

Published by the Acoustical Society of America

\section{ARTICLES YOU MAY BE INTERESTED IN}

Exploiting pattern transformation to tune phononic band gaps in a two-dimensional granular crystal

The Journal of the Acoustical Society of America 131, EL475 (2012); https://doi.org/10.1121/1.4718384

Erratum: A theoretical and numerical study on the mechanics of vibro-acoustic modulation [J. Acoust. Soc. Am. 141(4), 2821-2831 (2017)]

The Journal of the Acoustical Society of America 143, 2032 (2018); https://doi.org/10.1121/1.5031031

Perception of nonlinear distortion on emulation of frequency responses of headphones

The Journal of the Acoustical Society of America 143, 2085 (2018); https://doi.org/10.1121/1.5031030

Erratum: Strength and wave parameters for sound propagation in random media [J. Acoust. Soc. Am. 141(3), 2079-2092 (2017)]

The Journal of the Acoustical Society of America 143, 2164 (2018); https://doi.org/10.1121/1.5031783

Manipulating acoustic wave reflection by a nonlinear elastic metasurface

Journal of Applied Physics 123, 124901 (2018); https://doi.org/10.1063/1.5015952

A distributed subband valley fusion (DSVF) method for low frequency broadband target localization

The Journal of the Acoustical Society of America 143, 2269 (2018); https://doi.org/10.1121/1.5031782 


\title{
Erratum: Exploiting pattern transformation to tune phononic band gaps in a two-dimensional granular crystal [J. Acoust. Soc. Am. 131, EL475-EL480 (2012)]
}

\author{
Fatih Goncu, ${ }^{1}$ Stefan Luding, ${ }^{1}$ and Katia Bertoldi ${ }^{2, a)}$ \\ ${ }^{1}$ Multiscale Mechanics, University of Twente, Enschede, 7500 AE, Netherlands \\ ${ }^{2}$ Harvard John A. Paulson School of Engineering and Applied Science, Harvard University, Cambridge, \\ Massachusetts 02138, USA
}

(Received 28 March 2018; accepted 29 March 2018; published online 18 April 2018)

https://doi.org/10.1121/1.5031784

[JFL]

Pages: 2182-2183

The authors mistyped three entries in the $\mathbf{K}^{p q}$ stiffness matrix reported in Eq. (2). The correct entries should read

$$
\begin{aligned}
& K_{35}^{p q}=-k_{t} R^{p}, \\
& K_{55}^{p q}=+k_{t}, \\
& K_{63}^{p q}=k_{t} R^{p} R^{q} .
\end{aligned}
$$

However, it should be noted that this is only a typo in the text and the implementation of the stiffness matrix in the code used to compute the dispersion relations is correct.

Moreover, the authors used the wrong values of moment of inertia in the mass matrix. The error was due to a mistake in unit conversion. In the paper we adopted [mm], [N], and [s] as base units of length, force and time, respectively. In the chosen unit system the consistent unit for mass is tonnes, i.e., $10^{3} \mathrm{~kg}$. Therefore, the unit of moment of inertia is tonnes mm ${ }^{2}$. During the computation of the moment of inertia the radii of the disks were given in centimeters instead of millimeters. As such, the values of moment of inertia used in the manuscript are

$$
\mathbf{M}=\operatorname{diag}\left\{M_{p}, M_{p}, I_{p}, M_{q}, M_{q}, I_{q}\right\},
$$

entering in Eq. (4) in the manuscript:

$$
\begin{array}{ll}
I=1.0308 \times 10^{-07} \text { tonnes } \mathrm{mm}^{2} & \text { for rubber disks with } 5 \mathrm{~mm} \text { radius, } \\
I=1.3192 \times 10^{-08} \text { tonnes } \mathrm{mm}^{2} & \text { for teflon disks with } 2.5 \mathrm{~mm} \text { radius, } \\
I=6.4427 \times 10^{-09} \text { tonnes } \mathrm{mm}^{2} & \text { for rubber disks with } 2.5 \mathrm{~mm} \text { radius, }
\end{array}
$$
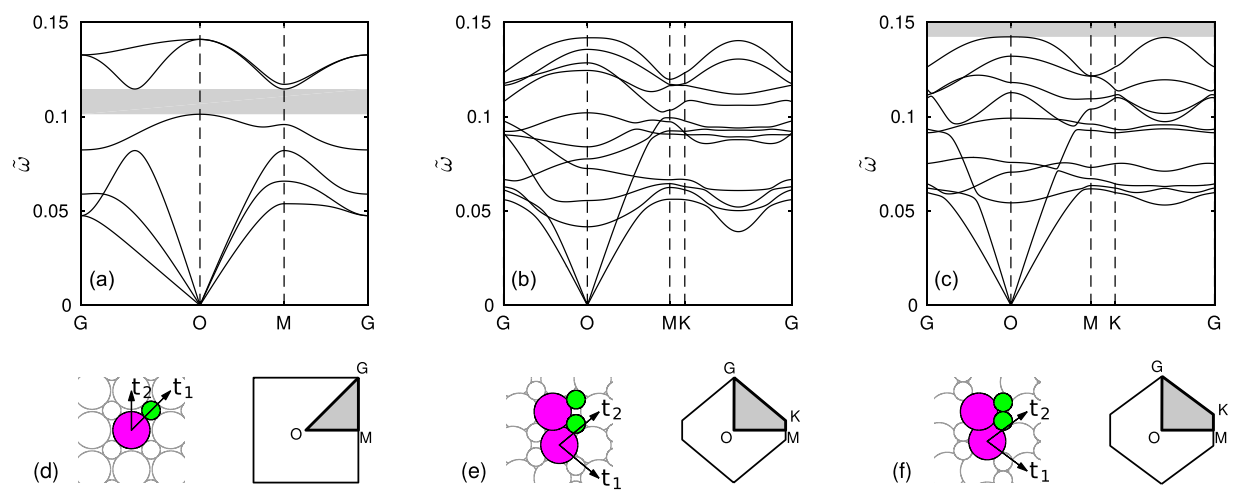

FIG. 2. (Color online) Top: Dispersion curves of the bi-disperse granular crystal composed of large rubber (5 mm) and small PTFE (2.5 mm) particles with tangential stiffness $k_{t}=0.1481 \times k_{n}$ at (a) $0 \%$, (b) $15 \%$, and (c) $25 \%$ uniaxial compression. The vertical axes represent the non-dimensional frequencies $\tilde{\omega}=\omega A /\left(2 \pi c_{r}^{10}\right)$ with $A=\left(\left\|\mathbf{t}_{1}\right\|+\left\|\mathbf{t}_{2}\right\|\right) / 2$. Bottom: Unit cells, lattice vectors $\mathbf{t}_{1}$ and $\mathbf{t}_{2}$ and the first Brillouin zones of the crystal at (d) $0 \%$, (e) $15 \%$, and (f) $25 \%$ uniaxial compression. The shaded areas indicate the irreducible parts of the Brillouin zones.

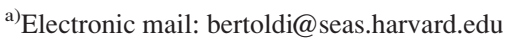



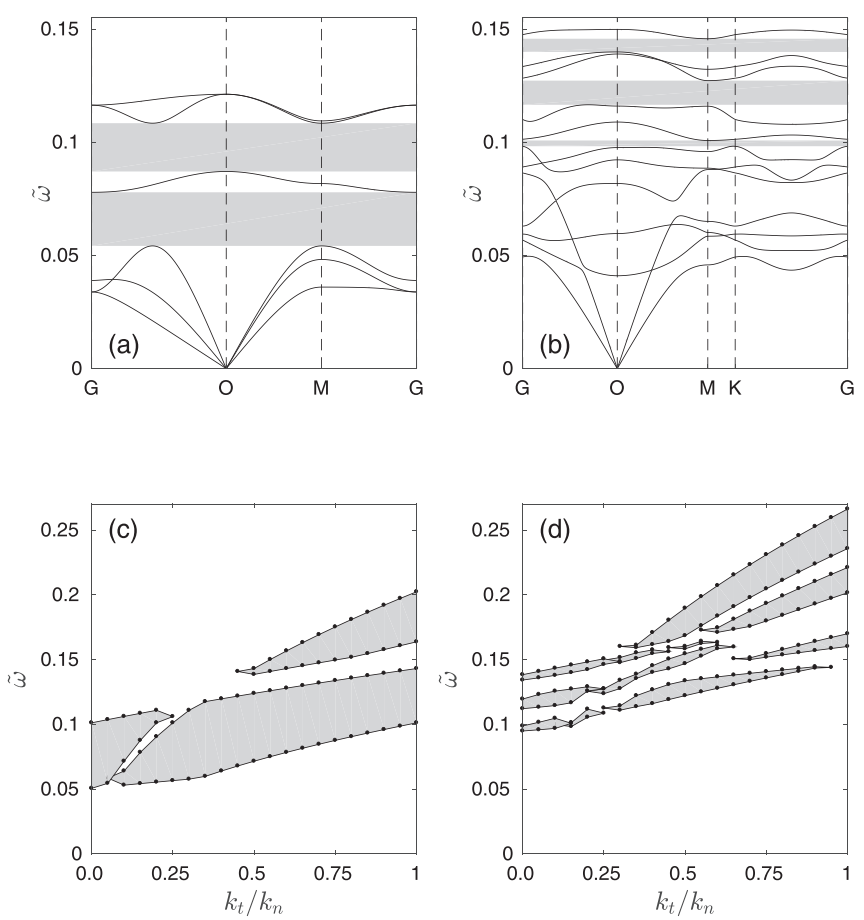

FIG. 3. Dispersion relation of a soft granular crystal made of rubber particles in the (a) undeformed and (b) patterned state (at $25 \%$ compression) with $k_{t} / k_{n}=0.1481$. Evolution of the bandgaps in the (c) undeformed and (d) patterned soft granular crystal as function of the stiffness ratio $k_{t} / k_{n}$.

which are 100 times less than the correct values:

$$
\begin{array}{ll}
I=1.0308 \times 10^{-05} \text { tonnes } \mathrm{mm}^{2} & \text { for rubber disks with } 5 \mathrm{~mm} \text { radius, } \\
I=1.3192 \times 10^{-06} \text { tonnes } \mathrm{mm}^{2} & \text { for teflon disks with } 2.5 \mathrm{~mm} \text { radius } \\
I=6.4427 \times 10^{-07} \text { tonnes } \mathrm{mm}^{2} & \text { for rubber disks with } 2.5 \mathrm{~mm} \text { radius. }
\end{array}
$$

It should be noted that the mistake is limited to the moment of inertia and mass values used in the calculations are correct. As such, the dispersion curves shown in Figs. 2 and 3 of the manuscript are incorrect. Below are the correct results.

The lower moment of inertia values in the manuscript lead to higher overall frequencies. We confirmed that by increasing the stiffness ratio $k_{t} / k_{n} \approx 10$ dispersion curves in similar frequency ranges can be obtained. However, the lower frequency band gaps present in the manuscript cannot be reproduced with the current values of the moment of inertia. This indicates that the band gaps are also influenced by the ratio of mass over moment of inertia of the particles in addition to the stiffness ratio. Nevertheless, the main conclusion of the paper remains valid, that is, the band gaps of the crystal change with deformation.

The authors would like to thank Nidhish Jain and Jongmin Shim for spotting the errors. 